\title{
Cell signaling during Trypanosoma cruzi invasion
}

\section{Fernando Y. Maeda, Cristian Cortez and Nobuko Yoshida*}

Departamento de Microbiologia, Imunologia e Parasitologia, Escola Paulista de Medicina, Universidade Federal de São Paulo, São Paulo, São Paulo, Brazil

\section{Edited by:}

Wanderley De Souza, Universidade Federal do Rio de Janeiro, Brazil

\section{Reviewed by:}

David M. Engman, Northwestern University, USA

Wanderley De Souza, Universidade Federal do Rio de Janeiro, Brazil

\section{*Correspondence:}

Nobuko Yoshida, Departamento de Microbiologia, Imunologia e Parasitologia, Escola Paulista de Medicina, Universidade Federal de São Paulo, Rua Pedro de Toledo, 669 - $6^{\circ}$ andar, 04039-032 São

Paulo, São Paulo, Brazil. e-mail:nyoshida@unifesp.br
Cell signaling is an essential requirement for mammalian cell invasion by Trypanosoma cruzi. Depending on the parasite strain and the parasite developmental form, distinct signaling pathways may be induced. In this short review, we focus on the data coming from studies with metacyclic trypomastigotes (MT) generated in vitro and tissue culturederived trypomastigotes (TCT), used as counterparts of insect-borne and bloodstream parasites, respectively. During invasion of host cells by MT or TCT, intracellular $\mathrm{Ca}^{2+}$ mobilization and host cell lysosomal exocytosis are triggered. Invasion mediated by MT surface molecule gp82 requires the activation of mammalian target of rapamycin (mTOR), phosphatidylinositol 3-kinase (PI3K), and protein kinase C (PKC) in the host cell, associated with $\mathrm{Ca}^{2+}$-dependent disruption of the actin cytoskeleton. In MT, protein tyrosine kinase, $\mathrm{PI} 3 \mathrm{~K}$, phospholipase C, and PKC appear to be activated. TCT invasion, on the other hand, does not rely on mTOR activation, rather on target cell $\mathrm{PI} 3 \mathrm{~K}$, and may involve the host cell autophagy for parasite internalization. Enzymes, such as oligopeptidase B and the major T. cruzi cysteine proteinase cruzipain, have been shown to generate molecules that induce target cell $\mathrm{Ca}^{2+}$ signal. In addition, TCT may trigger host cell responses mediated by transforming growth factor $\beta$ receptor or integrin family member. Further investigations are needed for a more complete and detailed picture of $T$. cruzi invasion.

Keywords: Trypanosoma cruzi, cell invasion, cell signaling, $\mathrm{Ca}^{2+}$ mobilization, metacyclic rypomastigote, tissue culture trypomastigote

\section{INTRODUCTION}

The hallmark of host cell invasion by Trypanosoma cruzi, a process that involves diverse parasite and host cell components, is the activation of signal transduction pathways leading to elevation in cytosolic $\mathrm{Ca}^{2+}$ concentration in both cells (Docampo and Moreno, 1996; Burleigh and Andrews, 1998; Yoshida, 2006). $\mathrm{Ca}^{2+}$-dependent disruption of host cell actin cytoskeleton that follows interaction with T. cruzi facilitates the mobilization of lysosomes to the cell periphery, where the fusion with the plasma membrane contributes for the biogenesis of parasitophorous vacuole, inhibition of this event resulting in impaired parasite internalization (Tardieux et al., 1992; Rodriguez et al., 1995; Martins et al., 2011).

Studies with metacyclic trypomastigotes (MT) generated in vitro and tissue culture-derived trypomastigotes (TCT), used as counterparts of insect-borne and bloodstream parasites, respectively, have disclosed that these developmental forms engage distinct sets of molecules and diverse strategies to induce host cell $\mathrm{Ca}^{2+}$ signaling and lysosomal exocytosis required for their internalization. Here we summarize the data from experiments performed mostly with non-phagocytic mammalian cells, aiming at understanding the signaling events that lead to T. cruzi invasion.

\section{MT SURFACE MOLECULES THAT TRIGGER HOST CELL SIGNALING DURING INVASION}

Adhesion to host cells is the first step for T. cruzi invasion. Surface glycoproteins with cell adhesion properties expressed in MT, such as gp90, gp82, gp30, and gp35/50, which are differentially expressed in different strains, bind to target cells in a receptormediated manner and trigger signaling pathways that may result or not in efficient parasite internalization (Yoshida, 2006).

Gp82, identified by the monoclonal antibody (mAb) 3F6, is a MT-specific surface molecule (Teixeira and Yoshida, 1986). It is a member of a multigene family that belongs to the gp85/transsialidase superfamily (Araya et al., 1994). Several pieces of evidence indicate that gp 82 is engaged by highly infective T. cruzi strains to enter host cells (Ramirez et al., 1993; Cortez et al., 2012a). Gp82 is conserved among T. cruzi strains from divergent genetic groups, displaying $>90 \%$ peptide sequence identity (Maeda et al., 2011). MT invasion mediated by gp82 triggers the target cell signaling cascades that result in cytosolic $\mathrm{Ca}^{2+}$ mobilization, an event detectable in mammalian cells susceptible to T. cruzi infection, such as HeLa and Vero cells, but not in T. cruzi-resistant K562 cells (Ruiz et al., 1998). Following gp82 recognition by its still undefined receptor, the available data indicate that $\mathrm{Ca}^{2+}$ is released from thapsigargin-sensitive stores, independent of inositol 1,4,5triphosphate $\left(\mathrm{IP}_{3}\right)$, or upon activation of phospholipase $\mathrm{C}$ (PLC), generating diacylglycerol (DAG) and $\mathrm{IP}_{3}$, the former activates protein kinase $\mathrm{C}$ (PKC) and the latter promotes $\mathrm{Ca}^{2+}$ release from $\mathrm{IP}_{3}$-sensitive compartments such as endoplasmic reticulum (ER; Ferreira et al., 2006; Maeda et al., 2012; Figure 1A). In addition to PKC, two other kinases participate in gp82-mediated MT invasion, namely the mammalian target of rapamycin (mTOR), a conserved Ser/Thr kinase that regulates diverse cell processes, and the lipid kinase phosphatidylinositol 3-kinase (PI3K), as suggests the diminished parasite invasion of cells pretreated with specific inhibitors of these enzymes (Martins et al., 2011; Figure 1A). What 


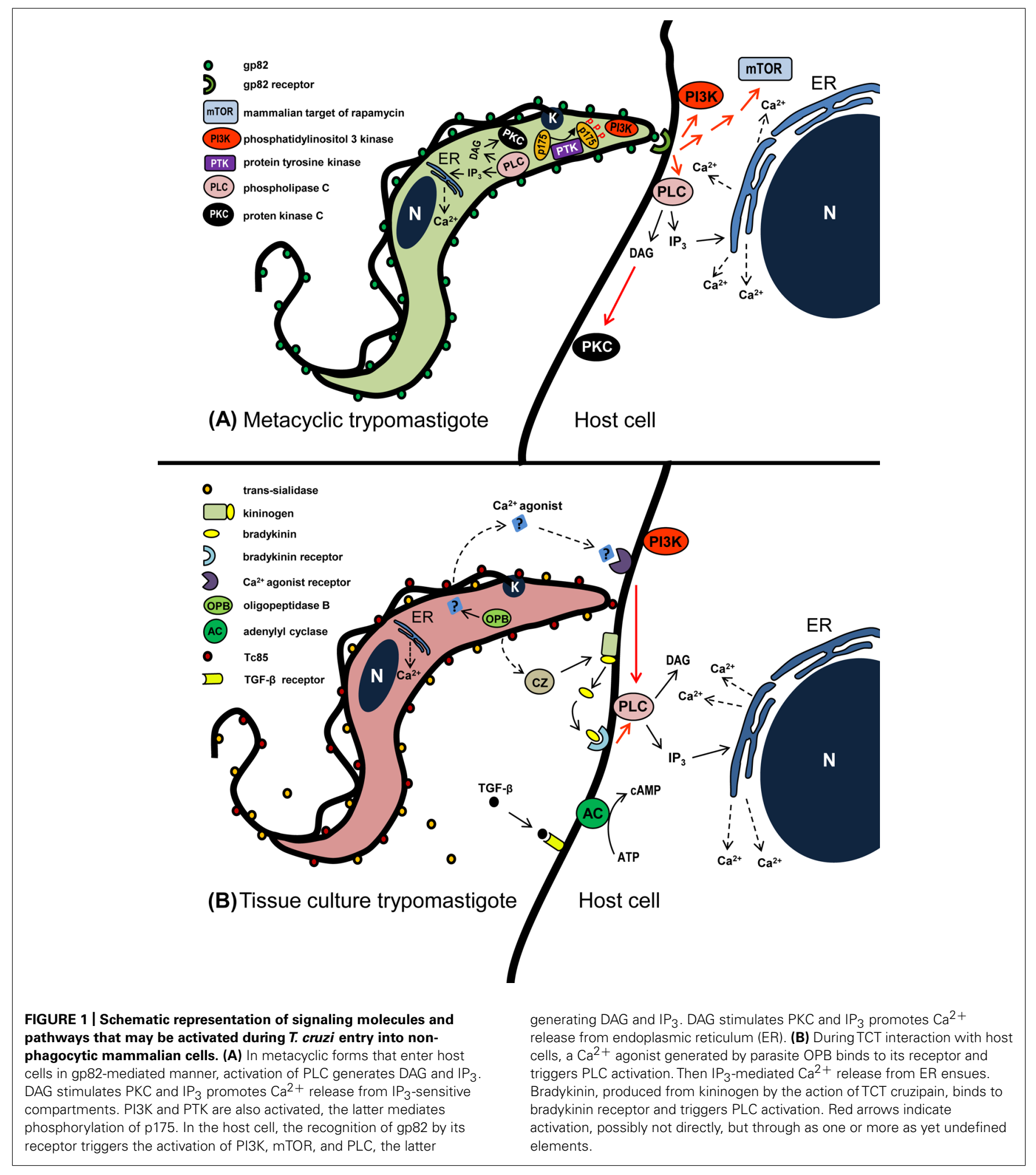

are the connections between these kinases can only be inferred at this point from data available in other systems. PI3K may act on mTOR signaling, provided that the phosphorylation of downstream effectors of mTOR, such as $\mathrm{S} 6 \mathrm{~K} 1$ and $4 \mathrm{E}-\mathrm{BP} 1$, is sensitive to rapamycin and also to PI3K inhibitor wortmannin (Chung et al.,
1994; Mèndez et al., 1996; Hay and Sonenberg, 2004). Another possible functional association is between PKC and mTOR. A pathway linking epidermal growth factor receptor to mTOR that was critically dependent on PKC has been described in glioma (Fan et al., 2009) and the association of a mTOR homolog with PKC 
has been demonstrated in Saccharomyces cerevisiae (Kumar et al., 2000). Under some circumstances, PI3K is activated upstream of PKC (Tong et al., 2000). Phosphatidylinositol-3,4,5- $\mathrm{P}_{3}$, a product of PI3K, appears to directly initiate cellular motility via PKC activation (Derman et al., 1997).

The elevation of cytosolic $\mathrm{Ca}^{2+}$ concentration induced by gp 82 promotes two associated events that facilitate MT invasion, namely the $\mathrm{Ca}^{2+}$-dependent actin cytoskeleton disruption and lysosome mobilization that culminates in exocytosis (Cortez et al., 2006; Martins et al., 2011; Figure 2). During gp82-mediated MT invasion, recently internalized parasites are seen within vacuoles that incorporated lysosome markers (Figure 2).

Gp30, a MT-specific surface molecule recognized by mAb 3F6 and expressed in gp82-deficient T. cruzi strains, is also implicated in cell invasion (Cortez et al., 2003, 2012a). Like gp82, binding of gp30 to target cells induces $\mathrm{Ca}^{2+}$ response and lysosome exocytosis, presumably through activation of signaling pathways involving PI3K, mTOR, and PKC (Cortez et al., 2003, 2012a). Gp30 and
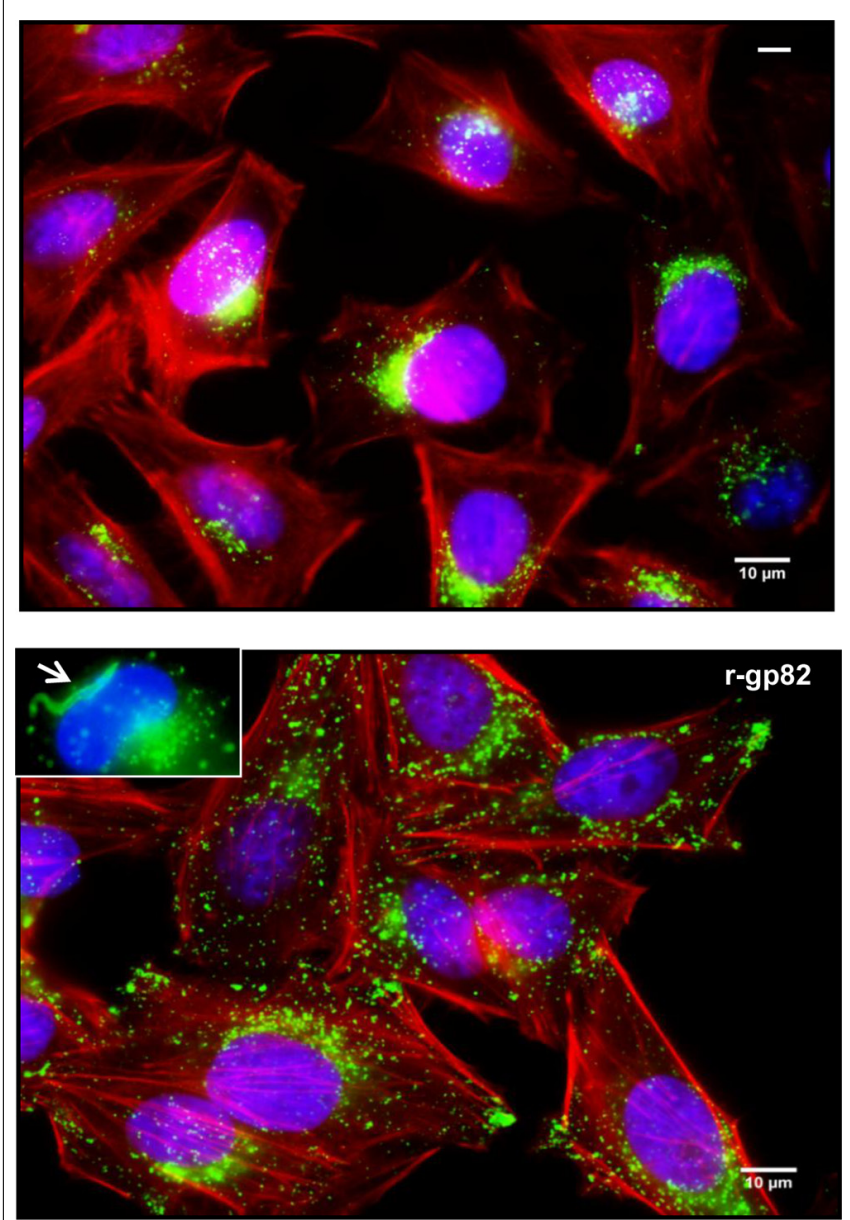

FIGURE 2 | Lysosome mobilization induced by MT gp82. Shown are HeLa cells incubated for $1 \mathrm{~h}$ in absence or in the presence of the recombinant protein (r-gp82) containing the complete gp82 sequence. Spread of lysosomes (green) from the perinuclear region to the cell periphery is induced by r-gp82. In the inset, recently internalized MT (arrow) inside the parasitophorous vacuole with lysosome marker is shown. gp82 are possibly recognized by the same receptor, as suggests the inhibition of host cell entry of both gp30- and gp82-expressing MT by mAb 3F6, as well as by recombinant proteins based on gp30 or gp82 (Cortez et al., 2003, 2012a).

In addition to gp82 or gp30, MT of different T. cruzi strains express variable levels of distinct isoforms of a stage-specific surface molecule gp90, which functions as a negative regulator of parasite infectivity (Málaga and Yoshida, 2001). Expression of gp90 at high levels is invariably associated with reduced capacity to enter target cells (Yoshida, 2006). As opposed to gp82 or gp30, and consistent with its role as down modulator of MT invasion, gp90 does not trigger $\mathrm{Ca}^{2+}$ signal upon binding to host cells (Ruiz et al., 1998).

Metacyclic trypomastigotes surface molecules gp35/50 recognized by mAb 10D8, expressed in poorly infective T. cruzi strains, are highly glycosylated mucin-like glycoproteins enriched in sialic acid and galactose residues that interact with target cells through their carbohydrate portion (Yoshida et al., 1989; Mortara etal., 1992; Schenkman etal., 1993b). Binding of gp35/50 to target cells triggers intracellular $\mathrm{Ca}^{2+}$ elevation, but to a lower degree than gp82 (Ruiz et al., 1998). Removal of sialic acid from gp35/50 increases the capacity to trigger target cell $\mathrm{Ca}^{2+}$ response and potentiates MT invasion (Yoshida et al., 1997). It appears therefore that sialyl residues impair parasite-host cell interaction and this is in contrast with the findings with TCT (Schenkman et al., 1991). Gp35/50-mediated invasion apparently requires F-actin recruitment, an event that may be associated with activation of adenylyl cyclase that generates cAMP (Ferreira et al., 2006).

The role played by MT secreted components in parasite internalization remains to be investigated. One such component, SAP (serine-, alanine-, and proline-rich protein), which binds to target cells in a receptor-dependent manner and induces $\mathrm{Ca}^{2+}$ signal, participates in the gp82-mediated internalization of MT but plays no role in gp35/50-mediated invasion (Baida et al., 2006). It is possible that SAP acts synergistically with gp82, by triggering $\mathrm{Ca}^{2+}$ signal that adds to the response induced by gp82.

\section{SIGNALING PATHWAYS ACTIVATED IN MT DURING INVASION}

Gp82-mediated invasion of host cells by MT triggers $\mathrm{Ca}^{2+}$ mobilization in the parasite, through signaling cascades involving PLC activation, generation of $\mathrm{DAG}$ and $\mathrm{IP}_{3}$, leading to $\mathrm{Ca}^{2+}$ release from $\mathrm{IP}_{3}$-sensitive reservoirs and PKC stimulation (Yoshida et al., 2000; Figure 1A). In addition to involvement of PI3K (Maeda et al., 2012), a protein tyrosine kinase (PTK) activation results in phosphorylation of $\mathrm{p} 175$, a protein undetectable in non-infective epimastigotes (Favoreto et al., 1998; Figure 1A). PTK activation and $\mathrm{Ca}^{2+}$ response are possibly associated events, provided that they are both affected by genistein (Yoshida et al., 2000), a PTK inhibitor that reduces MT infectivity (Neira et al., 2002). MT that invade host cells in a gp35/50-mediated manner may require cAMP and acidocalcisomes, the vacuoles containing a $\mathrm{Ca}^{2+} / \mathrm{H}^{+}$exchange system (Docampo et al., 1995), appear to be the main source of $\mathrm{Ca}^{2+}$ required for parasite internalization (Neira et al., 2002). 


\section{TCT-INDUCED SIGNALING EVENTS IN TARGET CELLS}

Diverse T. cruzi molecules, either secreted and/or expressed on the cell surface, have been implicated in TCT internalization. Among those known to have cell signal-inducing properties are cruzipain, trans-sialidase, trypomastigote small surface antigen (TSSA), and a soluble factor of undefined structure.

Cruzipain, the major T. cruzi cysteine proteinase expressed in all developmental forms of different strains (Murta et al., 1990; Paiva etal., 1998), participates in TCT internalization and in intracellular parasite development (Meirelles et al., 1992). From experiments using human umbilical vein endothelial cells or $\mathrm{CHO}$ cells overexpressing $B_{2}$ type of bradykinin receptor $\left(B_{2} R\right)$, it was postulated that cruzipain acts on cell-bound kininogen and generates bradykinin that, upon recognition by $\mathrm{B}_{2} \mathrm{R}$ triggers $\mathrm{IP}_{3}$ mediated $\mathrm{Ca}^{2+}$ influx (Scharfstein et al., 2000; Figure 1B), thus promoting parasite invasion, a mechanism that is not ubiquitous, its activation depending on the cell type and the parasite isolate used. Higher expression of functional cruzipain does not correlate with parasite infectivity (Paiva et al., 1998).

Trypanosoma cruzi trans-sialidase (TS), an enzyme that specifically transfers alpha (2-3)-linked sialic acid from host-derived macromolecules to parasite surface molecules, facilitates TCT invasion by sialylating a TCT-specific epitope Ssp-3, which is recognized by target cells through its sialic acid residues and whose signaling properties are unknown (Schenkman et al., 1991). TS may function as a TCT ligand to host cell alpha 2,3-sialyl receptors as a prelude to invasion (Ming et al., 1993). Signaling activities of TS toward mammalian cells include activation of PI3K/Akt pathway that contributes for survival of Schwann cells (Chuenkova et al., 2001), of mitogen-activated protein kinase (MAPK) or extracellular regulated kinase (ERK) pathways that induce neurite outgrowth in PC12 cells (Chuenkova and Pereira, 2001). TCT binds to TrkA, a receptor tyrosine kinase activated primarily by nerve growth factor, in a manner mediated by TS, inducing TrkA autophosphorylation and PI3K/Akt kinase signaling through TrkA-dependent mechanisms (Chuenkova and PereiraPerrin, 2004). Whether these TS-induced signaling mechanisms are associated with TCT invasion is not known. The participation of host cell sialic acid in TCT invasion has been inferred using Chinese hamster ovary cell mutant that is much less susceptible to infection than the parental cell line (Ciavaglia et al., 1993; Ming et al., 1993; Schenkman et al., 1993a). In macrophages, removal of sialic acid with neuraminidase or its blockage with cationized ferritin increased TCT uptake (Araújo Jorge and de Souza, 1984; Meirelles et al., 1984).

Recently, Cánepa et al. (2012) reported that peptides based on TSSA, a mucin-like molecule rich in serine and threonine predicted to be $O$-glycosylated (Di Noia et al., 2002), bind to mammalian cells and induce $\mathrm{Ca}^{2+}$ signaling. The question whether the native glycosylated TSSA and synthetic TSSA peptides share the same cell adhesion and signaling properties has not been addressed.

A secreted TCT factor of unknown structure has been claimed to trigger host cell $\mathrm{Ca}^{2+}$ mobilization in $\mathrm{IP}_{3}$-mediated manner (Rodriguez et al., 1995). According to Burleigh et al. (1997), the soluble TCT factor is produced by the action of cytosolic oligopeptidase $\mathrm{B}(\mathrm{OPB})$, an enzyme closely related to members of the prolyl oligopeptidase family of serine endopeptidases. The $\mathrm{Ca}^{2+}$ agonist, generated from a precursor molecule in TCT cytoplasm, would be exported and its recognition by a target cell receptor, followed by $\mathrm{PLC}$ activation and $\mathrm{IP}_{3}$ production, would release $\mathrm{Ca}^{2+}$ from ER (Caler et al., 1998; Figure 1B). OPB null TCT had a diminished cell invasion capacity, a $\mathrm{Ca}^{2+}$ signalinducing activity of low intensity and recruited lysosome in a significantly delayed fashion, but preserved the property to induce cAMP elevation in host cells (Caler et al., 2000), which is associated with the ability to potentiate $\mathrm{Ca}^{2+}$-regulated lysosomal exocytosis (Rodriguez et al., 1999). While the ability of $\mathrm{Ca}^{2+}$ agonist produced by OPB in disrupting F-actin filaments is associated with increased TCT invasion (Rodriguez et al., 1995), there are reports indicating that actin cytoskeleton disruption results in diminished TCT entry into different cell types, including heart muscle cells (Meirelles et al., 1999; Rosestolato et al., 2002).

Several TCT surface molecules with affinity for extracellular matrix have been implicated in host cell invasion, but little is known about their signal-inducing properties. Among such molecules is a laminin-binding glycoprotein encoded by a multigene Tc85 family belonging to the gp85/trans-sialidase superfamily (Giordano et al., 1999). Conserved in all members of gp85/trans-sialidase glycoprotein family is the FLY domain (VTVXNVFLYNR). Peptide based on FLY binds to cytokeratin 18 (CK18) on the surface of LLC-MK(2) epithelial cells and promotes dephosphorylation and CK18 reorganization, activating ERK1/2 signaling pathway that leads to increased TCT internalization (Magdesian et al., 2001). This finding with peptide FLY is unlikely to bear any association with TCT entry into host cells because FLY domain is almost completely buried (Cortez et al., 2012b), therefore unavailable for interaction with CK18. In support of this view, transient silencing of CK18 gene in RNAi-treated HeLa cells did not affect binding and invasion of TCT (Claser et al., 2008). Furthermore, a recombinant protein based on amastigote surface protein-2 containing FLY domain failed to bind CK18 (Claser et al., 2008), consistent with the fact that FLY domain is not exposed on the surface.

Cell signaling events during TCT internalization, without association with specific $T$. cruzi molecules, have been reported by many authors. In different cell types, activation of PI3K emerges as a common feature for TCT invasion process. PI3K activated by TCT facilitates lysosome-dependent parasite entry into nonpahgocytic cells (Woolsey et al., 2003). In target cells invaded by a significant fraction of TCT through an lysosome-independent pathway, there is the formation of a host cell plasma membranederived vacuole enriched in the lipid products of class I PI3 kinases, initially devoid of lysosomal markers and gradually acquiring lysosome associated membrane protein 1 (Woolsey et al., 2003). This lysosome-independent early event is compatible with the finding that the newly forming TCT compartments first interact with an early endosome and subsequently with other late endosomes, before interaction with lysosomes (Wilkowsky et al., 2002). Using blood trypomastigotes and macrophages, Todorov et al. (2000) found that class I and class III PI3-kinase activities are involved in parasite internalization. PI3K recruitment and assembly of actin filaments were detected at the site of TCT interaction with macrophages (Vieira et al., 2002). In non-phagocytic 
Vero, $\mathrm{L}_{6} \mathrm{E}_{9}$ and NIH $3 \mathrm{~T} 3$ cells, as well as in human and $\mathrm{J774}$ murine macrophages, PI3K inactivation was ascertained using specific PI3K inhibitors (Wilkowsky et al., 2001). Concomitant with PI3K activation, a strong activation of protein kinase B (PKB/Akt) occurs and, accordingly, transiently transfected cells containing an inactive mutant PKB are more resistant to infection by TCT as compared to the active mutant-transfected cells (Wilkowsky et al., 2001).

Tissue culture-derived trypomastigotes invasion of macrophages also requires PTKs (Vieira et al., 1994). Tyrosinephosphorylated residues accumulate at the site of TCT association with the cell surface, co-localizing with macrophage F-actin-rich domains (Vieira etal., 2002). Activation of macrophage PKC induced by recombinant gp83, a TCT surface ligand, was also reported (Villalta et al., 1999). Protein phosphatases may also play a role in TCT internalization. Tyrosine dephosphorylation of several proteins is induced by TCT in $\mathrm{L}_{6} \mathrm{E}_{9}$ myoblasts and the cells, either treated with protein tyrosine phosphatase inhibitors or in the presence of excess phosphotyrosine, become more resistant to invasion by TCT (Zhong et al., 1998). The involvement of alkaline phosphatase has been deduced from experiments with human HEp2 tumor cells that, upon inhibition of the enzyme activity, exhibited a different pattern of actin organization and reduced susceptibility to TCT invasion (Sartori et al., 2003).

Several other host cell components have been implicated in TCT invasion. Ming et al. (1995) found that TCT induce a transforming growth factor $\beta$ (TGF- $\beta$ )-responsive reporter gene in TGF- $\beta$-sensitive cell lines, and epithelial cells lacking TGF- $\beta$ receptor I or II, or with dysfunction of the intracellular signaling cascade due to constitutive expression of the cyclin-dependent kinase cdk4 or of the oncogene H-Ras, were more refractory to penetration by TCT. In experiments with human coronary artery smooth muscle cells expressing galectin-3, which increases K-Ras activation and triggers a Ras signal (Elad-Sfadia et al., 2004), there was a decreased TCT adhesion to cells with reduced expression of galectin-3, which was restored by exogenous galectin-3 (Kleshchenko et al., 2004). The $\beta 1$ subunit of VLA integrin family that links the extracellular matrix to the cortical cytoskeleton was reported to be involved in TCT entry into human macrophages (Fernandez etal., 1993). Recently, acid sphingomyelinase (ASM) was claimed to be required for TCT invasion. Inhibition or depletion

\section{REFERENCES}

Araújo Jorge, T., and de Souza, W. (1984). Effect of carbohydrates, periodate and enzymes in the process of endocytosis of Trypanosoma cruzi by macrophages. Acta Trop. 41, 17-28.

Araya, J. E., Cano, M. I., Yoshida, N., and da Silveira, J. F. (1994). Cloning and characterization of a gene for the stage-specific $82-\mathrm{kDa}$ surface antigen of metacyclic trypomastigotes of Trypanosoma cruzi. Mol. Biochem. Parasitol. 65, 161-169.

Baida, R. C., Santos, M. R., Carmo, M. S., Yoshida, N., Ferreira, D., Ferreira, A. T., et al. (2006). Molecular characterization of serine-, alanine-, and proline-rich proteins of Trypanosoma cruzi and their possible role in host cell infection. Infect. Immun. 74, 1537-1546.

Burleigh, B. A., and Andrews, N. W. (1998). Signaling and host cell invasion by Trypanosoma cruzi. Curr. Opin. Microbiol. 1, 451-465.

Burleigh, B. A., Caler, E. V., Webster, P., and Andrews, N. W. (1997). A cytosolic serine endopeptidase from Trypanosoma cruzi is required for the generation of $\mathrm{Ca}^{2+}$ signaling in mammalian cells. J. Cell Biol. 136, 609-620.

Caler, E. V., Morty, R. E., Burleigh, B. A., and Andrews, N. W. (2000). Dual role of signaling pathways leading to $\mathrm{Ca}^{2+}$ and cyclic AMP elevation

of lysosomal ASM markedly reduced the target cell susceptibility to TCT invasion, whereas extracellular addition of ASM stimulated endocytosis, enhanced parasite entry, and restored normal invasion levels in ASM-depleted cells, and ceramide, the product of sphingomyelin hydrolysis, was detected in newly formed parasitophorous vacuoles containing TCT (Fernandes et al., 2011). Triggering of autophagy was also associated with TCT internalization. Romano et al. (2009) have shown that treatment of host cells with mTOR inhibitor rapamycin increased lysosomaldependent TCT invasion by inducing autophagy. This finding is in sharp contrast with gp82-mediated MT invasion that is inhibited by rapamycin (Martins etal., 2011). Also contrasting with gp82-mediated MT internalization that is impaired in cells prestarved for a short time (Martins et al., 2011), condition that triggers the autophagic pathway, TCT invasion increased upon prestarvation of target cells (Romano et al., 2009). In addition, the absence of Atg5 or the reduced expression of Beclin 1 , proteins required at the initial steps of autophagosome formation, reduced the association of parasitophorous vacuole with the lysosomal marker Lamp-1 and diminished TCT entry (Romano et al., 2009).

\section{CONCLUDING REMARKS}

What emerges from the data on signaling events during host cell invasion by $T$. cruzi is a still fragmentary picture. Although many parasite as well as host cell components have been identified as playing roles in MT or TCT invasion, these may represent only a small part of the repertoire available for the accomplishment of the critical step for infection. The whole process is beginning to be understood at the molecular level. Furthermore, how the diverse elements are connected and what are the sequences of reactions that culminate in intracellular rearrangements that facilitate parasite internalization have as yet to be clarified. Therefore, a formidable task is still ahead before we can more fully understand the intricate functioning of molecular and cellular machinery involved in T. cruzi invasion.

\section{ACKNOWLEDGMENTS}

Work supported by Fudação de Amparo à Pesquisa do Estado de São Paulo (FAPESP) and Conselho Nacional de Desenvolvimento Cientifico e Tecnológico (CNPq).

in host cell invasion by Trypanosoma cruzi. Infect. Immun. 68, 6602-6610.

Caler, E. V., Vaena de Avalos, S., Haynes, P. A., Andrews, N. W., and Burleigh, B. A. (1998). Oligopeptidase B-dependent signaling mediates host cell invasion by Trypanosoma cruzi. EMBO J. 17, 4975-4986.

Cánepa, G. E., Degese, M. S., Budu, A., Garcia, C. R. S., and Buscaglia, C. A. (2012). Involvement of TSSA (trypomastigote small surface antigen) in Trypanosoma cruzi invasion of mammalian cells. Biochem. J. 444, 211-218.

Chuenkova, M. V., Furnari, F. B., Cavenee, W. K., and Pereira, M. A. (2001). Trypanosoma cruzi trans-sialidase: a potent and specific survival factor for human Schwann cells by means of phosphatidylinositol 3-kinase/Akt signaling. Proc. Natl. Acad. Sci. U.S.A. 98, 9936-9941.

Chuenkova, M. V., and Pereira, M. A. (2001). The T. cruzi trans-sialidase induces PC12 cell differentiation via MAPK/ERK pathway. Neuroreport 4, 3715-3718.

Chuenkova, M. V., and PereiraPerrin, M. (2004). Chagas' disease parasite promotes neuron survival and differentiation through TrkA nerve growth factor receptor. J. Neurochem. 91, 385-394.

Chung, J., Grammer, T. C., Lemon, K. P., Kazlauskas, A., and Blenis, 
J. (1994). PDGF- and insulindependent pp70S6k activation mediated by phosphatidylinositol-3-OH kinase. Nature 370, 71-75.

Ciavaglia, M. C., Carvalho, T. U., and De Souza, W. (1993). Interaction of Trypanosoma cruzi with cells with altered glycosylation patterns. Biochem. Biophys. Res. Commun. 193, 718-721.

Claser, C., Curcio, M., de Mello, S. M., Silveira, E. V., Monteiro, H. P., and Rodrigues, M. M. (2008). Silencing cyotkeratin 18 gene inhibits intracellular replication of Trypanosoma cruzi in HeLa cells but not binding and invasion of Trypanosomes. BMC Cell Biol. 9, 68. doi: 10.1186/14712121-9-68

Cortez, C., Martins, R. M., Alves, R. M., Silva, R. C., Bilches, L. C., Macedo, S., et al. (2012a). Differential infectivity by the oral route of Trypanosoma cruzi lineages derived from Y strain. PLoS Negl. Trop. Dis. 6, e1804. doi: 10.1371/journal.pntd.0001804

Cortez, C., Yoshida, N., Bahia, D., and Sobreira, T. J. P. (2012b). Structural basis of the interaction of a Trypanosoma cruzi surface molecule implicated in oral infection with host cells and gastric mucin. PLoS ONE 7, e42153. doi: 10.1371/journal.pone. 0042153

Cortez, M., Atayde, V., and Yoshida, N. (2006). Host cell invasion mediated by Trypanosoma cruzi surface molecule gp82 is associated with F-actin disassembly and is inhibited by enteroinvasive Escherichia coli. Microbes Infect. 8, 1502-1512.

Cortez, M., Neira, I., Ferreira, D., Luquetti, A. O., Rassi, A., Atayde, V. D., etal. (2003). Infection by Trypanosoma cruzi metacyclic forms deficient in gp82 but expressing a related surface molecule gp30. Infect. Immun. 71, 6184-6191.

Derman, M. P., Toker, A., Hartwig, J. H., Spokes, K., Falck, J. R., Chen, C. S., et al. (1997). The lipid products of phosphoinositide 3-kinase increase cell motility through protein kinase C. J. Biol. Chem. 272, 6465-6470.

Di Noia, J. M., Buscaglia, C. A., De Marchi, C. R., Almeida, I. C., and Frasch, A. C. (2002). A Trypanosoma cruzi small surface molecule provides the first immunological evidence that Chagas' disease is due to a single parasite lineage. J. Exp. Med. 195, 401-413.

Docampo, R., and Moreno, S. N. (1996). The role of $\mathrm{Ca}^{2+}$ in the process of cell invasion by intracellular parasites. Parasitol. Today 12, 61-65.

Docampo, R., Scott, D. A., Vercesi, A. E., and Moreno, S. N. (1995). Intracellular $\mathrm{Ca}^{2+}$ storage in acidocalcisomes of Trypanosoma cruzi. Biochem. J. 310, 1005-1012.

Elad-Sfadia, G., Haklai, R., Balan, E. and Kloog, Y. (2004). Galectin-3 augments K-Ras activation and triggers a Ras signal that attenuates ERK but not phosphoinositide 3-kinase activity. J. Biol. Chem. 279, 34922-34930.

Fan, Q. W., Cheng, C., Knight, Z. A., Haas-Kogan, D., Stokoe, D., James, C. D., et al. (2009). EGFR signals to mTOR through PKC and independently of Akt in glioma. Sci. Signal. 2, ra4.

Favoreto, S. Jr., Dorta, M. L., and Yoshida, N. (1998). Trypanosoma cruzi $175-\mathrm{kDa}$ protein tyrosine phosphorylation is associated with host cell invasion. Exp. Parasitol. 89, 188-194.

Fernandes, M. C., Cortez, M., Flannery, A. R., Tam, C., Mortara, R. A., and Andrews, N. W. (2011). Trypanosoma cruzi subverts the sphingomyelinasemediated plasma membrane repair pathway for cell invasion. J. Exp. Med. 208, 909-921.

Fernandez, M. A., Munoz-Fernandez M. A., and Fresno, M. (1993). Involvement of beta 1 integrins in the binding and entry of Trypanosoma cruzi into human macrophages. Eur. J. Immunol. 23, 552-557.

Ferreira, D., Cortez, M., Atayde, V. D., and Yoshida, N. (2006) Actin cytoskeleton-dependent and independent host cell invasion by Trypanosoma cruzi is mediated by distinct parasite surface molecules. Infect. Immun. 74, 5522-5528.

Giordano, R., Fouts, D. L., Tewari, D. Colli, W., Manning, J. E., and Alves, M. J. M. (1999). Cloning of a surface membrane glycoprotein specific for the infective form of Trypanosoma cruzi having adhesive properties to laminin. J. Biol. Chem. 274, 34613468.

Hay, N., and Sonenberg, N. (2004). Upstream and downstream of mTOR. Genes Dev. 18, 1926-1945.

Kleshchenko, Y. Y., Moody, T. N., Furtak V. A., Ochieng, J., Lima, M. F., and Villalta, F. (2004). Human galectin-3 promotes Trypanosoma cruzi adhesion to human artery smooth muscle cells. Infect. Immun. 72, 6717-6721.

Kumar, V., Panadey, P., Sabatini, D., Kumar, M., Majumder, P. K., Bharti, A., etal. (2000). Functional interaction between RAFT1/FRAP/mTOR and protein kinase $\mathrm{C} \delta$ in the regulation of cap-dependent initiation of translation. EMBO J. 19, 1087-1097.

Maeda, F. Y., Alves, R. M., Cortez, C., Lima, F. M., and Yoshida, N. (2011). Characterization of the infective properties of a new genetic group of Trypanosoma cruzi associated with bats. Acta Trop. 120, 231-237.

Maeda, F. Y., Cortez, C., Alves, R. M., and Yoshida, N. (2012). Mammalian cell invasion by closely related Trypanosoma species $T$. dionisii and T. cruzi. Acta Trop. 121, 141-147.

Magdesian, M. H., Giordano, R., Ulrich, H., Juliano, M. A., Juliano, L., Schumacher, R. I., et al. (2001). Infection by Trypanosoma cruzi: identification of a parasite ligand and its hostcell receptor. J. Biol. Chem. 276, 19382-19389.

Málaga, S., and Yoshida, N. (2001). Targeted reduction in expression of Trypanosoma cruzi surface glycoprotein gp90 increases parasite infectivity. Infect. Immun. 69, 353-359.

Martins, R. M., Alves, R. M., Macedo, S., and Yoshida, N. (2011). Starvation and rapamycin differentially regulate host cell lysosome exocytosis and invasion by Trypanosoma cruzi metacyclic forms. Cell. Microbiol. 13, 943-954.

Meirelles, M. N., Juliano, L., Carmona, E., Silva, S. G., Costa, E. M., Murta, A. C., et al. (1992) Inhibitors of the major cysteinyl proteinase (gp57/51) impair host cell invasion and arrest the intracellular development of Trypanosoma cruzi in vitro. Mol. Biochem. Parasitol. 52, 175-184.

Meirelles, M. N., Pereira, M. C., Singer, R. H., Soeiro, M. N., Garzoni, L. R., Silva, D. T., et al. (1999) Trypanosoma cruzi-cardiomyocytes: new contributions regarding a better understanding of this interaction. Mem. Inst. Oswaldo Cruz 94(Suppl. 1), 149-152.

Meirelles, M. N., Souto-Padrón, T. and de Souza, W. (1984). Participation of cell surface anionic sites in the interaction between Trypanosoma cruzi and macrophages. J. Submicrosc. Cytol. 16, 533-545.

Mèndez, R., Myers, M. G. Jr., White, M. F., and Rhoads, R. E. (1996). Stimulation of protein synthesis, eukaryotic translation initiation factor $4 \mathrm{E}$ phosphorylation, and PHAS-I phosphorylation by insulin requires insulin receptor substrate and phosphatidylinositol 3-kinase. Mol. Cell. Biol. 16, 2857-2864.

Ming, M., Chuenkova, M., OrtegaBarria, E., and Pereira, M. E. (1993). Mediation of Trypanosoma cruzi invasion by sialic acid on the host cell and trans-sialidase on the Trypanosome. Mol. Biochem. Parasitol. 59, 243-252.

Ming, M., Ewen, M. E., and Pereira, M. E. A. (1995). Trypanosome invasion of mammalian cells requires activation of the TGF- $\beta$ signaling pathway. Cell 82, 287-296.

Mortara, R. A., da Silva, S., Araguth, M. F., Blanco, S. A., and Yoshida, N. (1992). Polymorphism of the 35- and 50-kilodalton surface glycoconjugates of Trypanosoma cruzi metacyclic trypomastigotes. Infect. Immun. 60, 4673-4678.

Murta, A. C., Persechini, P. M., Padron, S., de Souza, W., Guimarães, J. A., and Scharfstein, J. (1990). Structural and functional identification of gp57/51 antigen of Trypanosoma cruzi as a cysteine proteinase. Mol. Biochem. Parasitol. 43, 27-38.

Neira, I., Ferreira, A. T., and Yoshida, N. (2002). Activation of distinct signal transduction pathways in Trypanosoma cruzi isolates with differential capacity to invade host cells. Int. J. Parasitol. 32, 405-414.

Paiva, C. N., Padron, T. S., Costa, D. A., and Gattass, C. R. (1998). High expression of a functional cruzipain by a non-infective and nonpathogenic Trypanosoma cruzi clone. Parasitology 117, 483-490.

Ramirez, M. I., Ruiz, R. C., Araya, J. E., da Silveira, J. F., and Yoshida, N. (1993). Involvement of the stage-specific 82-kilodalton adhesion molecule of Trypanosoma cruzi metacyclic trypomastigotes in host cell invasion. Infect. Immun. 61, 36363641.

Rodriguez, A., Martinez, I., Chung, A., Berlot, C. H., and Andrews, N. W. (1999). cAMP regulates $\mathrm{Ca}^{2+}$ dependent exocytosis of lysosomes and lysosome-mediated cell invasion by trypanosomes. J. Biol. Chem. 274, 6754-16759.

Rodriguez, A., Rioult, M. G., Ora, A., and Andrews, N. W. (1995). A trypanosome-soluble factor induces IP3 formation, intracellular $\mathrm{Ca}^{2+}$ mobilization and microfilament rearrangement in host cells. J. Cell Biol. 129, 1263-1273.

Romano, P. S., Arboit, M. A., Vásquez, C. L., and Colombo, M. I. (2009). The autophagic pathway is a key component in the lysosomal dependent entry of Trypanosoma cruzi into the host cell. Autophagy 5, 6-18.

Rosestolato, C. T. F., Dutra, J. M. F., De Souza, W., and Carvalho, T. M. U. (2002). Participation of host cell actin filaments during interaction of trypomastigote forms of Trypanosoma cruzi with host cells. Cell Struct. Funct. 27, 91-98.

Ruiz, R. C., Favoreto, S. Jr., Dorta, M L., Oshiro, M. E. M., Ferreira, A. T., Manque, P. M., et al. (1998). Infectivity of Trypanosoma cruzi strains 
is associated with differential expression of surface glycoproteins with differential $\mathrm{Ca}^{2+}$ signaling activity. Biochem. J. 330, 505-511.

Sartori, M. J., Mezzano, L., Lin, S., Munoz, S., and Fabro, S. P. (2003). Role of placental alkaline phosphatase in the internalization of trypomastigotes of Trypanosoma cruzi into HEp2 cells. Trop. Med. Int. Health 8, 832-839.

Scharfstein, J., Schmitz, V., Morandi, V., Capella, M. M. A., Lima, A. P. C. A., Morrot, A., et al. (2000) Host cell invasion by Trypanosoma cruzi is potentiated by activation of bradykinin B2 receptors. J. Exp. Med. 192, 1289-1299.

Schenkman, R. P., Vandekerckhove, F., and Schenkman, S. (1993a). Mammalian cell sialic acid enhances invasion by Trypanosoma cruzi. Infect. Immun. 61, 898-902.

Schenkman, S., Ferguson, M. A., Heise, N., Cardoso de Almeida, M. L., Mortara, R. A., and Yoshida, N. (1993b). Mucin-like glycoproteins linked to the membrane by glycosylphosphatidylinositol anchor are the major acceptors of sialic acid in a reaction catalyzed by trans-sialidase in metacyclic forms of Trypanosoma cruzi. Mol. Biochem. Parasitol. 59, 293-304.

Schenkman, S., Jiang, M. Hart., G. W., and Nussenzweig, V. (1991). A novel cell surface trans-sialidase of Trypanosoma cruzi generates a stagespecific epitope required for invasion of mammalian cells. Cell 65, 11171125.

Tardieux, I., Webster, P., Ravesloot, J., Boron, W., Lunn, J. A., Heuser, J.
E., et al. (1992). Lysosome recruitment and fusion are early events required for Trypanosoma invasion of mammalian cells. Cell 71, 11171130.

Teixeira, M. M. G., and Yoshida, N. (1986). Stage-specific surface antigens of metacyclic trypomastigotes of Trypanosoma cruzi identified by monoclonal antibodies. Mol. Biochem. Parasitol. 18, 271-282.

Todorov, A. G., Einicker-Lamas, M. Castro, S. L., Oliveira, M. M. and Guilherme, A. (2000). Activation of host cell phosphatidylinositol 3-kinases by Trypanosoma cruzi infection. J. Biol. Chem. 275, 3218232186.

Tong, H., Chen, W., Steenbergen, C., and Murphy, E. (2000). Ischemic reconditioning activates phosphatidylinositol-3-kinase upstream of protein kinase C. Circ. Res. 87, 309-315.

Vieira, M., Dutra, J. M., Carvalho, T. M., Cunha-e-Silva, N. L., Souto-Padrón, T., and de Souza, W. (2002). Cellular signaling during the macrophage invasion by Trypanosoma cruzi. Histochem. Cell Biol. 118, 491-500.

Vieira, M. C. F., Carvalho, T. U., and Souza, W. (1994). Effect of protein kinase inhibition on the invasion process of macrophages by Trypanosoma cruzi. Biochem. Biophys. Res. Commun. 203, 967-971.

Villalta, F., Zhang, Y., Bibb, K. E., Pratap, S., Burns, J. M. Jr., and Lima, M. F. (1999). Signal transduction in human macrophages by gp 83 ligand of Trypanosoma cruzi: trypomastigote gp83 ligand up-regulated trypanosome entry through protein kinase C activation. Mol. Cell Biol. Res. Commun. 2, 64-70.

Wilkowsky, S. E., Barbieri, M. A., Stahl, P., and Isola, E. L. D. (2001). Trypanosoma cruzi: phosphatidylinositol 3-kinase and protein kinase $\mathrm{B}$ activation is associated with parasite invasion. Exp. Cell Res. 264, 211-218. Wilkowsky, S. E., Barbieri, M. A., Stahl, P. D., and Isola, E. L. D. (2002). Regulation of Trypanosoma cruzi invasion of nonphagocytic cells by the endocytically active GTPases dynamin, Rab5, and Rab7. Biochem. Biophys. Res. Commun. 291, 516-521.

Woolsey, A. M., Sunwoo, L., Petersen, C. A., Brachmann, S. M., Cantley, L. C., and Burleigh, B. A. (2003). Novel PI 3-kinase-dependent mechanisms of trypanosome invasion and vacuole maturation. J. Cell Sci. 116, 3611-3622.

Yoshida, N. (2006). Molecular basis of mammalian cell invasion by Trypanosoma cruzi. An. Acad. Bras. Ciênc. 78, 87-111.

Yoshida, N., Dorta, M. L., Ferreira, A. T., Oshiro, M. E., Mortara, R. A., AcostaSerrano, A., et al. (1997). Removal of sialic acid from mucin-like surface molecules of Trypanosoma cruzi metacyclic trypomastigotes enhances parasite-host cell interaction. Mol. Biochem. Parasitol. 84, 57-67.

Yoshida, N., Favoreto, S. Jr., Ferreira, A. T., and Manque, P. M. (2000). Signal transduction induced in Trypanosoma cruzi metacyclic trypomastigotes during the invasion of mammalian cells. Braz. J. Med. Biol. Res. 33, 269-278.

Yoshida, N., Mortara, R. A., Araguth, M. F., Gonzalez, J. C., and Russo,
M. (1989). Metacyclic neutralizing effect of monoclonal antibody 10D8 directed to the 35 and 50 kilodalton surface glycoconjugates of Trypanosoma cruzi. Infect. Immun. 57, 1663-1667.

Zhong, L., Lu, H. G., Moreno, S. N., and Docampo, R. (1998). Tyrosine phosphate hydrolysis of host proteins by Trypanosoma cruzi is linked to cell invasion. FEMS Microbiol. Lett. 161, 15-20.

Conflict of Interest Statement: The authors declare that the research was conducted in the absence of any commercial or financial relationships that could be construed as a potential conflict of interest.

Received: 29 August 2012; paper pending published: 30 September 2012; accepted: 12 November 2012; published online: 28 November 2012.

Citation: Maeda FY, Cortez $C$ and Yoshida $N$ (2012) Cell signaling during Trypanosoma cruzi invasion. Front. Immun. 3:361. doi: 10.3389/fimmu. 2012.00361

This article was submitted to Frontiers in Microbial Immunology, a specialty of Frontiers in Immunology.

Copyright (c) 2012 Maeda, Cortez and Yoshida. This is an open-access article distributed under the terms of the Creative Commons Attribution License, which permits use, distribution and reproduction in other forums, provided the original authors and source are credited and subject to any copyright notices concerning any third-party graphics etc. 